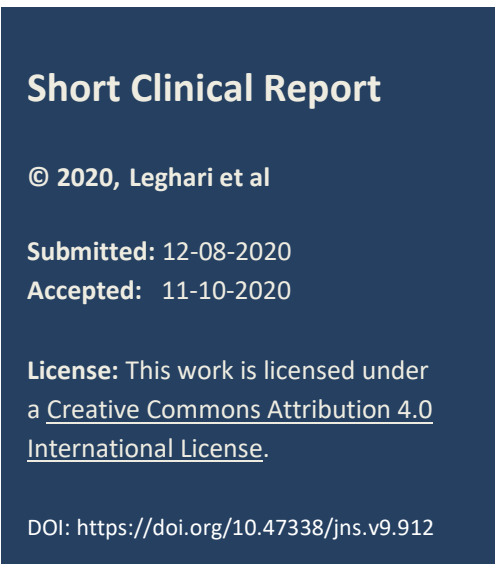

\title{
Cerebriform Nevus Sebaceous: a rare lesion
}

Abdul Lateef Leghari, ${ }^{* 1}$ Muhammad Bilal Mirza, ${ }^{2}$ Nabila Talat, ${ }^{2}$ Waseem Humayoun, ${ }^{3}$

1 Medical College, Aga Khan University Hospital, Karachi

2 Department of Pediatric Surgery II, The Children's Hospital and the Institute of Child Health, Lahore

3 Department of Plastic Surgery, The Children's Hospital and the Institute of Child Health, Lahore

Correspondence*: Abdul Lateef Leghari, Medical College, Aga Khan University Hospital, Karachi

E-mail: abdullateefleghari@gmail.com

\section{CASE PRESENTATION}

A 15-day-old neonate presented with a wrinkled skin lesion on the left temporoparietal region that was extending up to the lateral canthus of the left eye. The lesion had a cerebriform appearance, and measured $12 \mathrm{~cm}$ in length, while the width was variable along the length, however width in greatest dimension was $5 \mathrm{~cm}$ (Fig. 1).

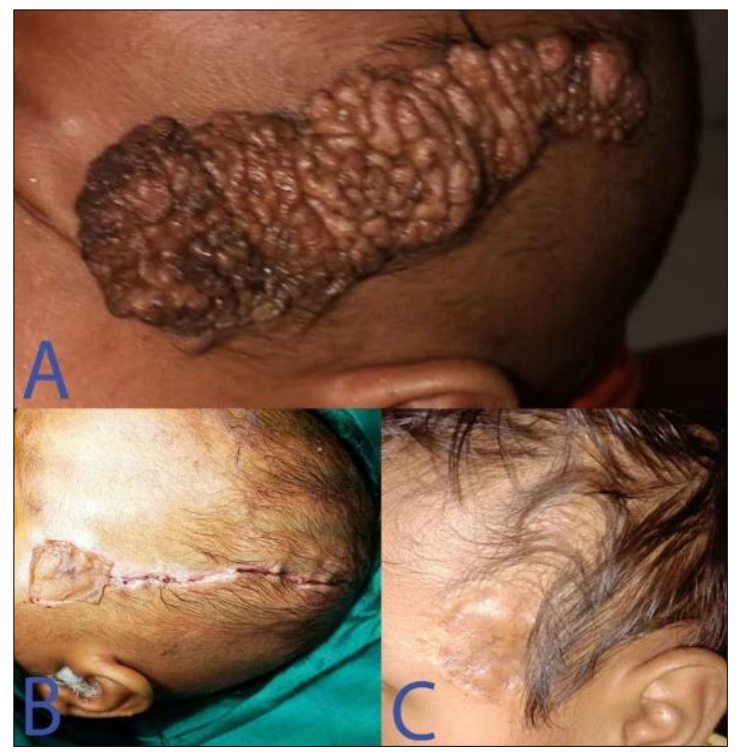

Figure 1: (A) Preoperative image showing cerebriform lesion (B) Peroperative image (C) Follow-up at 2 years showing a healed wound with acceptable scarring.

Ocular and neurological examinations were unremarkable. Elective Procedure was planned, and all preoperative workup was unremarkable. Intraoperatively, a copious amount of sebum was present in the rugosities. The lesion was excised, and the wound was approximated superiorly and covered with splitthickness skin graft at the base where it was the widest. Histology reported the lesion as Nevus Sebaceous. The patient has been followed for 2 years and serial examinations have revealed no abnormal findings.

\section{DISCUSSION}

Nevus sebaceous (NS) appears as a wellcircumscribed raised lesion, usually irregular in shape owing to the distribution of sebaceous glands, commonly over the head and neck.[1] Lesions at other sites are rare.[1] the cerebriform variant of NS is even rarer. NS comprises of abnormalities in the epidermis which may be acanthotic or papillomatous, sweat and sebaceous glands, and hair follicles; consistent observation particularly on NS of the scalp is almost or absolute absence of mature hair follicles.[1] The glands have great variability in the irregularity of morphology and distribution, showing periodic enlargement during infancy due to maternal hormones.[1]

Multiple benign neoplasms demonstrating RAS mutations have been observed to complicate NS. mostly syringocystadenoma papilliferum and trichoblastomalike proliferations.[2,3] Although rare, malignant tumors such as basal cell carcinoma (BCC) may be seen, with incidences as high as $20 \%$. [2] However recent studies have classified what was earlier diagnosed as BCC in NS as trichoblastoma.[2] The neoplasms are observed rather more frequently in adults, and although rare this does not exclude the possibility of malignancy in children, thus justifying prophylactic excision as in our case, sometimes even necessitating reconstruction after extensive surgical resection. [4]

Mohs Micrographic Surgery has been suggested, which involves continuous microscopic examination of the resected tissue, in cases in whom secondary neoplastic growth is observed however, this requires a modern setup and efficient coordination between the surgical theatre and histopathology department.[4] Since our case didn't show any signs of secondary neoplastic growth therefore there was no need for this procedure. The role of tissue expanders has also been suggested; however, they have their drawbacks, and 
among others staged interventions, and extensive follow-up schedule, we therefore simply opted for split-thickness skin graft since there was minimal skin deficiency.

\section{Acknowledgements: Nil}

Conflict of Interest: MBM and NT are members of the editorial team, however the manuscript was independently handled by another editor and they were not involved in the decision making of this manuscript.

\section{REFERENCES}

1. Mishra K, Jandial A, Khadwal A, Malhotra P. Cerebriform nevus. BMJ Case Rep [Internet]. 2017;2017:bcr2017222402. Available from: https://pubmed.ncbi.nlm.nih.gov/28942417

2. Namiki T, Miura K, Ueno M, Arima Y, Nishizawa A, Yokozeki $\mathrm{H}$. Four different tumors arising in a nevus sebaceous. Case Rep Dermatol [Internet]. 2016 Apr 20;8:75-9. Available from: https:// pubmed.ncbi.nlm.nih.gov/27194974

\section{Source of Support: Nil}

Consent to Publication: Author(s) declared taking informed written consent for the publication of clinical photographs/material (if any used), from the legal guardian of the patient with an understanding that every effort will be made to conceal the identity of the patient, however it cannot be guaranteed.

Author Contributions: Author(s) declared to fulfil authorship criteria as devised by ICMJE and approved the final version.

3. Aslam A, Salam A, Griffiths CEM, McGrath JA. Naevus sebaceous: a mosaic RAS opathy. Clin Exp Dermatol. 2014; 39:1-6.

4. Taher M, Feibleman C, Bennett R. Squamous cell carcinoma arising in a nevus sebaceous of Jadassohn in a 9-year-old girl: treatment using Mohs micrographic surgery with literature review. Dermatologic Surg. 2010; 36:1203-8. 